\title{
Management of Chronic Gingivitis with localized periodontitis by Nonsurgical (Phase I) Periodontal Therapy- A Case Report.
}

\author{
Khan $\mathrm{M} \mathrm{H} \mathrm{I}^{1}$, Eka S A², lqbal $\mathrm{M} \mathrm{A}^{3}$
}

Received: 18.09.2017

Accepted: 11.10.2017

Abstract:

Periodontitis is a chronic inflammatory disease of the periodontal tissues (periodontium) which surround and support the teeth, that results in attachment loss and alveolar bone destruction leads to ultimate tooth loss. It is caused by the bacteria present in dental plaque, which is a tenacious substance that forms on teeth and gingiva just after teeth are brushed. Periodontal treatment is aimed at controlling the infection in order to stop the progression of the disease and to be able to maintain a healthy periodontium. Mechanical debridement of supragingival and subgingival biofilms, together with adequate oral hygiene measures is the standard periodontal therapy. This mechanical subgingival biofilm debridement consists of an initial (nonsurgical /phase I) phase involving scaling and root planing (SRP) and the elimination of plaque retentive factors, followed by a surgical phase (if needed) including the elevation of a tissue flap and bone remodeling in further stages. The adjunct use of antibiotics has proven to additionally improve the outcome of periodontal treatment. A clinical case of a 40-years-old male patient with generalized severe chronic periodontitis with localized gingival swelling was treated with nonsurgical (phase I) periodontal therapy that was confined to oral hygiene instruction (OHI), SRP with an adjunct antimicrobial regimen.

Key words: Chronic periodontitis, nonsurgical /phase I therapy, scaling and root planing (SRP).

1. Dr. Md. Huzzatul Islam Khan, B.D.S., Lecturer \& Dental Surgeon, Dept. of Periodontology \& Oral Pathology, Update Dental College \& Hospital, Dhaka.

2. Dr. Sultana Akter Eka, BDS, Update Dental College \& Hospital, Dhaka.

3. Dr. Md. Ashif Iqbal, B.D.S., D.D.S., Associate Professor \& Head of Dept. of Periodontology \& Oral Pathology, Update Dental College \& Hospital, Dhaka.

Correspondence : Dr. Md. Huzzatul Islam Khan, E-mail: hiksaimum@gmail.com 


\section{Introduction}

It is scientifically established that dental plaque is the primary etiological factor in the pathogenesis of periodontal diseases and many epidemiological studies clearly state the relation between dental calculus and periodontitis ${ }^{[1,2]}$. Calcified bacterial plaque is known as dental calculus. The degree of mineralization in supragingival and subgingival calculus is different, but both are masked by a layer of bacterial plaque [3, 4]. Relationship of calculus with periodontal pathogens and bacterial by-products makes it somewhat difficult to investigate its etiological role alone in periodontitis. Yet, it is widely accepted that calculus is a local contributory factor ${ }^{[5]}$. Calculus, having a rough surface and porous structure, is an ideal substrate for bacterial colonization and serve as a reservoir for toxic bacterial components and antigen ${ }^{[6]}$. Porphyromonas gingivalis, Treponema denticola, and Aggregatibacter actinomycetemcomitans have been identified within supra- and subgingival calculus ${ }^{[7-9]}$. Calcifying nanoparticles are found in dental plaque may contribute to the formation of calculus and pathogenic calcification of epithelial cells ${ }^{[10]}$. Localized periodontal inflammation can persist, leading to the breakdown of supporting tissues, if left untreated. Because of this, removal of subgingival plaque and calculus is a must need procedure for successful periodontal therapy. Supragingival calculus can be seen through naked eye examination, but clinical detection of subgingival calculus relies on tactile exploration of tooth surfaces with an explorer or probe. Calculus on interproximal surfaces may be detected by periodontal probe and more accurately by intra-oral periapical radiographs, although the accuracy of detection depends on radiographic projections ${ }^{[11]}$. The superior periapical radiographs can only detect $43.8 \%$ of the proximal surfaces that is verified visually after extraction ${ }^{[12]}$. Advanced technologies, including dental endoscopes [13], fiber-optic probes [14], autofluorescence ${ }^{[15]}$, and lasers ${ }^{[16]}$, are being used recently to better detect subgingival calculus. Although it is difficult to remove subgingival calculus completely by scaling and root planing (SRP) ${ }^{[17,18]}$, periodontal healing is noticed even in the presence of microscopically visible calculus ${ }^{[19]}$. Initial /nonsurgical stage of periodontal therapy usually results in significant clinical improvement and change of subgingival microbial flora ${ }^{[20,21]}$. This report documents the treatment of a patient with generalized severe chronic periodontitis with localized gingival swelling using nonsurgical /phase I periodontal therapy.

\section{Case Description}

A 40-year-old male presented for a consultation in the outdoor patient department (OPD) of Update Dental College \& Hospital, Dhaka, Bangladesh. He gave a history of taking betel nuts and betel quids with chewing tobacco. Throughout his life, he did never visit any dentist for dental treatment. After intra-oral examination, dental surgeon of OPD detected supra and subgingival plaque, calculus, bleeding on probing, periodontal pockets around maxillary and mandibular molars, premolars and on the anterior regions. A localized gingival swelling was also found in the lower right anterior region between lateral incisor and canine (Figure:1 \& 2).

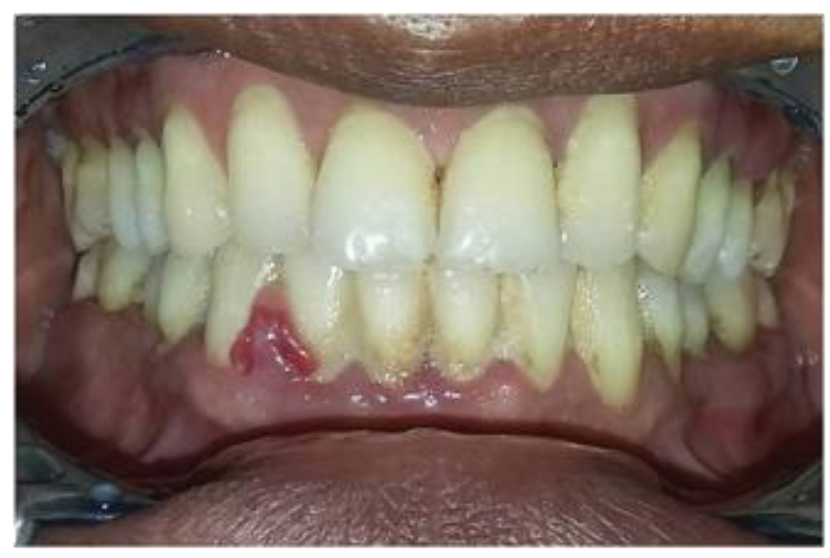

Figure: 1. Showing accumulation of plaque and calculus

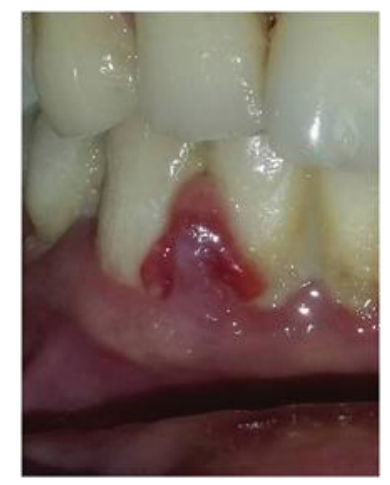

Figure: 2 Showing localized gingival swelling between lower right lateral incisor and canine

The Dental surgeon referred him to the Periodontology OPD. The patient was advised for intra-oral periapical radiographs from the radiology department. The radiographs revealed the presence of $40 \%$ alveolar bone loss lower right lateral incisor and canine (Figure: 3). Patient's oral hygiene was poor with plaque index score 2 and clinical signs of inflamma- 
tion around all teeth were severe. Gingival index score was 3. Average sulcus depth was $3 \mathrm{~mm}$.

Based on the radiographic and clinical findings a nonsurgical treatment plan was developed to address the patient's plaque induced chronic generalized severe gingivitis with localized moderate periodontitis and gingival swelling. SRP with an ultrasonic scaler, followed by adjunctive treatment with a five-day course of systemic Metronidazole $400 \mathrm{mg}$ three times a day. The patient was instructed to use a medi- umtuft brush to remove plaque and also dental floss as an interdental cleaning aid.

Periodontal re-assessment was performed one month after treatment, with an improvement shown with regard to the following parameters: marked reduction of gingival inflammation with gingival index score 1, complete resolution of localized gingival swelling, reduction in plaque (plaque index score 0 ) and bleeding on probing was absent (Figure: 4).

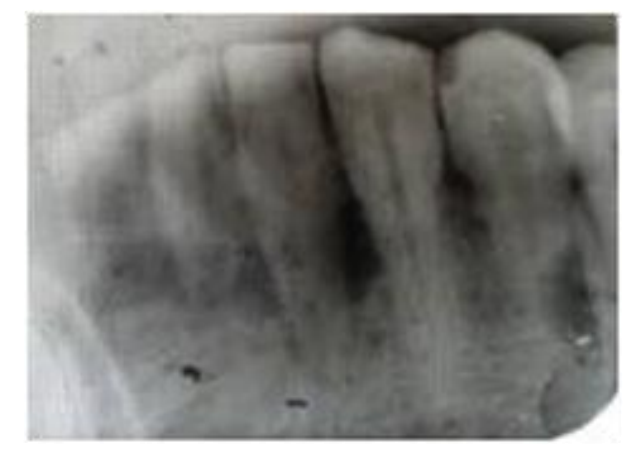

Figure: 3 Showing periapical radiograph localized alveolar bone loss between lower right lateral incisor and canine

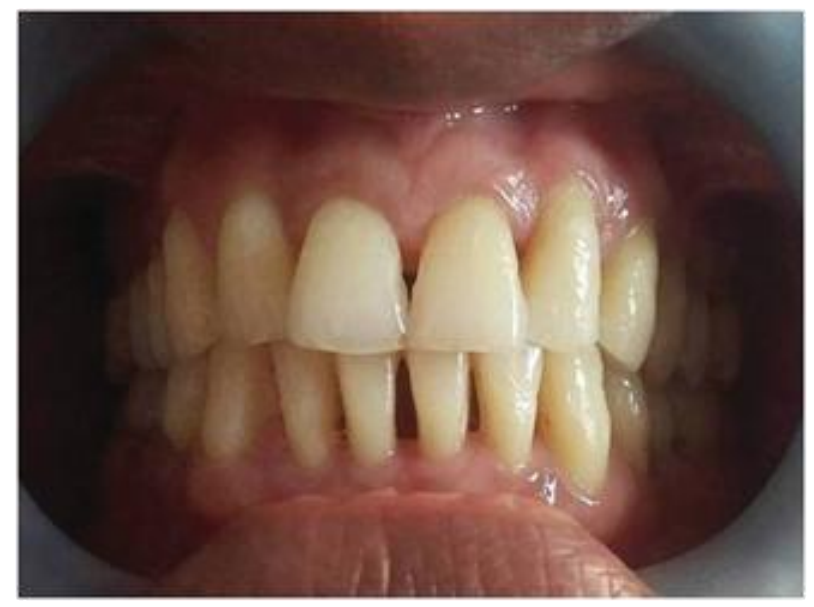

Figure: 4. Showing healthy gingiva with better oral hygiene and complete resolution of localized gingival swelling after a month.

\section{Discussion}

This case illustrates the periodontal treatment of a patient with generalized severe chronic periodontitis with localized gingival swelling using nonsurgical phase I periodontal therapy. In the first step after taking patient's oral hygiene practice information, carefully gave emphasis on brushing and interdental cleaning. Plaque control instructions were delivered to the patient. In the second step, supragingival and subgingival plaque and calculus were removed by SRP using ultrasonic scaler machine with universal insert type. SRP is still now regarded as the cornerstone of periodontal therapy. Its effectiveness in the treatment of chronic periodontitis accompanied by

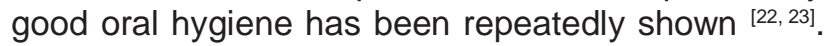
Subgingival calculus and plaque can be substantially removed by SRP [17,24,25], creating a favorable microenvironment for periodontal tissue healing. In this case, initial nonsurgical periodontal therapy reduced pocket depths. In some randomized clinical trials, it has been indicated that SRP of molars leads to a 0.67 to $1.2 \mathrm{~mm}$ mean reduction of periodontal pocket depth at sites initially 4 to $6 \mathrm{~mm}$ deep and 0.94 to $2 \mathrm{~mm}$ reduction at sites initially deeper than $6 \mathrm{~mm}$ ${ }^{[23]}$. Isidor and Karring ${ }^{[26]}$ reported a $3.7 \mathrm{~mm}$ reduction of periodontal pocket depth at sites with angular defects 12 months after SRP. The improvement presented in this case was consistent with these clinical studies. Nonsurgical periodontal treatment usually leads to the formation of a long junctional epithelium ${ }^{[27}$, and partial bone fill in an infrabony periodontal defect can also occasionally occur following careful SRP. Hwang, et al. ${ }^{[28]}$ reported an increase in bone density in sites with more than $3 \mathrm{~mm}$ vertical alveolar bone loss after SRP. Reduction of radiographic defect depth was a positively associated use of adjunctive antibiotics ${ }^{[29]}$. It is very difficult to attain complete removal of plaque and calculus in deep pockets, indicated in previous studies [17,18,30]. Residual calculus amount is significantly correlated with pocket depth ${ }^{[17,31]}$. The favorable treatment outcome observed in this patient could be attributable to several factors. The patient maintained a satisfactory level of oral hygiene throughout his treatment in our department. Adjunctive administration of Metronidazole may have also enhanced the outcome. The clinical benefits obtained from adjunctive systemic antimicrobials can justify their use in patients with periodontal disease ${ }^{[32]}$. It is clear that detection of oral disease at sites that are difficult to access can be challenging. If the patient had visited a dental hospital or clinic, it should have been possible to detect the 
presence of calculus, inflammation, deep probing depths, and bone loss at an earlier point in time.

\section{Conflict of Interests}

The authors have no conflict of interests to declare.

\section{References}

[1] M. F. Timmerman and G. A. van der Weijden, "Risk factors for periodontitis," International Journal of Dental Hygiene, vol. 4, no. 1, pp. 2-7, 2006.

[2] A. Anerud, H. Loe, and H. Boysen, "The natural history and cli- " nical course of calculus formation in man," Journal of Clinical Periodontology, vol. 18, no. 3, pp. 160-170, 1991.

[3] J. Friskopp, "Ultrastructure of nondecalcified supragingival and subgingival calculus," Journal of Periodontology, vol. 54, no. 9, pp. 542-550, 1983.

[4] E. A. Roberts-Harry and V. Clerehugh, "Subgingival calculus: where are we now? A comparative review," Journal of Dentistry, vol. 28, no. 2, pp. 93-102, 2000.

[5] D. J. White, "Dental calculus: recent insights into occurrence, formation, prevention, removal and oral health effects of supragingival and subgingival deposits," European Journal of Oral Sciences, vol. 105, no. 5, part 2, pp. 508-522, 1997.

[6] S. Jepsen, J. Deschner, A. Braun, F. Schwarz, and J. Eberhard, "Calculus removal and the prevention of its formation," Periodontology 2000, vol. 55, no. 1, pp. 167188, 2011.

[7] N. Calabrese, P. Galgut, and N. Mordan, "Identification of Actinobacillus actinomycetemcomitans, Treponema denticola and Porphyromonas gingivalis within human dental calculus: a pilot investigation," Journal of the International Academy of Periodontology, vol. 9, no. 4, pp. 118128, 2007.

[8] B. T. K. Tan, N. J. Mordan, J. Embleton, J. Pratten, and P. N. Galgut, "Study of bacterial viability within human supragingival dental calculus," Journal of Periodontology, vol. 75, no. 1, pp. 23-29, 2004.

[9] N. N. Moolya, S. Thakur, S. Ravindra, S. B. Setty, R. Kulkarni, and K. Hallikeri, "Viability of bacteria in dental calculus-a microbiological study," Journal of Indian Society of Periodontology, vol. 14, no. 4, pp. 222-226, 2010.

[10] S.-M. Zhang, F. Tian, X.-Q. Jiang et al., "Evidence for calcifying nanoparticles in gingival crevicular fluid and dental calculus in Case Reports in Dentistry 5 periodontitis," Journal of Periodontology, vol. 80, no. 9, pp. 1462 1470, 2009.
[11] A. Tugnait, V. Clerehugh, and P. N. Hirschmann, "The usefulness of radiographs in diagnosis and management of periodontal diseases: a review," Journal of Dentistry, vol. 28, no. 4, pp. 219-226, 2000.

[12] S. A. Buchanan, R. S. Jenderseck, M. A. Granet, L. T. Kircos, D. W. Chambers, and P. B. Robertson, "Radiographic detection of dental calculus," Journal of Periodontology, vol. 58, no. 11, pp. 747-751, 1987.

[13] T. G. Wilson Jr., S. K. Harrel, M. E. Nunn, B. Francis, and K. Webb, "The relationship between the presence of tooth-borne subgingival deposits and inflammation found with a dental endoscope," Journal of Periodontology, vol. 79, no. 11, pp. 2029-2035, 2008.

[14] A. Kasaj, I. Moschos, B. Rohrig, and B. Willershausen, "The " effectiveness of a novel optical probe in subgingival calculus detection," International Journal of Dental Hygiene, vol. 6, no. 2, pp. 143-147, 2008.

[15] E. Kurihara, T. Koseki, K. Gohara, T. Nishihara, T. Ansai, and T. Takehara, "Detection of subgingival calculus and dentine caries by laser fluorescence," Journal of Periodontal Research, vol. 39, no. 1, pp. 59-65, 2004.

[16] Z. Badran, J. Demoersman, X. Struillou, H. Boutigny, P. Weiss, and A. Soueidan, "Laser-induced fluorescence for subgingival calculus detection: scientific rational and clinical application in periodontology," Photomedicine and Laser Surgery, vol. 29, no. 9, pp. 593-596, 2011.

[17] G. M. Rabbani, M. M. Ash Jr., and R. G. Caffesse, "The effectiveness of subgingival scaling and root planing in calculus removal," Journal of Periodontology, vol. 52, no. 3, pp. 119-123, 1981.

[18] T. J. Kepic, T. J. O'Leary, and A. H. Kafrawy, "Total calculus removal: an attainable objective?" Journal of Periodontology, vol. 61 , no. 1, pp. 16-20,1990.

[19] L. Blomlof, J. Friskopp, R. Appelgren, S. Lindskog, and L. " Hammarstrom, "Influence of granulation tissue, dental calculus " and contaminated root cementum on periodontal wound healing. An experimental study in monkeys," Journal of Clinical Periodontology, vol. 16, no. 1, pp. 27-32, 1989.

[20] M. A. Cugini, A. D. Haffajee, C. Smith, R. L. Kent Jr., and S. S. Socransky, "The effect of scaling and root planing on the clinical and microbiological parameters of periodontal diseases: 12- month results," Journal of Clinical Periodontology, vol. 27, no. 1, pp. 30-36, 2000.

[21] C. M. Cobb and J. Jeffcoat, "Clinical significance of non-surgical periodontal therapy: an evidence-based perspective of scaling and root planing," Journal of Clinical Periodontology, vol. 29, supplement 2, pp. 6-16, 2002. 
[22] J. Lindhe, E. Westfelt, S. Nyman, S. S. Socransky, and A. D. Haffajee, "Long-term effect of surgical/non-surgical treatment of periodontal disease," Journal of Clinical Periodontology, vol. 11, no. 7, pp. 448-458, 1984.

[23] L. J. A. Heitz-Mayfield, L. Trombelli, F. Heitz, I. Needleman, and D. Moles, "A systematic review of the effect of surgical debridement vs. non-surgical debridement for the treatment of chronic periodontitis," Journal of Clinical Periodontology, vol. 29, supplement 3, pp. 92-102, 2002.

[24] S. Thornton and J. Garnick, "Comparison of ultrasonic to hand instruments in the removal of subgingival plaque," Journal of Periodontology, vol. 53, no. 1, pp. 35-37, 1982.

[25] W. A. Jones and T. J. O'leary, "The effectiveness of in vivo root planning in removing bacterial endotoxin from the roots of periodontally involved teeth," Journal of Periodontology, vol. 49, no. 7, pp. 337-342, 1978.

[26] F. Isidor and T. Karring, "Long-term effect of surgical and nonsurgical periodontal treatment. A 5-year clinical study," Journal of Periodontal Research, vol. 21, no. 5, pp. 462-472, 1986.

[27] J. G. Caton and H. A. Zander, "The attachment between tooth and gingival tissues after periodic root planing and soft tissue curettage," Journal of Periodontology, vol. 50, no. 9, pp. 462-466, 1979.

[28] Y.-J. Hwang, M. J. Fien, S.-S. Lee et al., "Effect of scaling and root planing on alveolar bone as measured by subtraction radiography," Journal of Periodontology, vol. 79, no. 9, pp. 1663-1669, 2008.

[29] L. Nibali, D. Pometti, Y.-K. Tu, and N. Donos, "Clinical and radiographic outcomes following non-surgical therapy of periodontal infrabony defects: a retrospective study," Journal of Clinical Periodontology, vol. 38, no. 1, pp. 50-57, 2011.

[30] P. R. Sherman, L. H. Hutchens Jr., L. G. Jewson, J. M. Moriarty, G. W. Greco, and W. T. McFall Jr., "The effectiveness of subgingival scaling and root planning. I. Clinical detection of residual calculus," Journal of Periodontology, vol. 61, no. 1, pp. 3-8, 1990.

[31] J.Waerhaug, "Healing of the dento-epithelial junction following subgingival plaque control. I. As observed in human biopsy material," Journal of Periodontology, vol. 49, no. 1, pp. 1-8, 1978.

[32] D. Herrera, M. Sanz, S. Jepsen, I. Needleman, and S. Roldan, "A ' systematic review on the effect of systemic antimicrobials as an adjunct to scaling and root planing in periodontitis patients," Journal of Clinical Periodontology, vol. 29, supplement 3, pp. 136-159, 2002. 